\title{
A PROSPECTIVE STUDY TO KNOW THE AETIOLOGY AND THE FINAL OUTCOME OF HAEMOPTYSIS PATIENTS ATTENDING A TERTIARY CARE CENTRE IN NORTH INDIA
}

\author{
Sanjay Kumar Verma ${ }^{1}$, Brijesh Kumar ${ }^{2}$, Anand Kumar 3 , Chandra Sekhar ${ }^{4}$, Arun Sampath ${ }^{5}$, Rajendra Prasad 6 , Surya Kant ${ }^{7}$ \\ ${ }_{1}^{1}$ Assistant Professor, Department of Tuberculosis and Respiratory Diseases, Government Medical College, Kannauj, Uttar Pradesh. \\ ${ }^{2}$ Assistant Professor, Department of Internal Medicine, Government Medical College, Kannauj, Uttar Pradesh. \\ ${ }^{3}$ Assistant Professor and HOD, Department of Tuberculosis and Respiratory Diseases, GSVM Medical College, Kanpur. \\ $4 J u n i o r$ Resident, Department of Tuberculosis and Respiratory Diseases, GSVM Medical College, Kanpur. \\ ${ }^{5}$ Consultant Pulmonologist, Miot International Hospitals, Chennai. \\ ${ }^{6}$ Professor and HOD, Department of Pulmonary Medicine, Era's Lucknow Medical College, Lucknow. \\ 7 Professor and HOD, Department of Pulmonary Medicine, King George's Medical University, Uttar Pradesh.
}

ABSTRACT
BACKGROUND
This study was designed to analyse the different aetiologies, severity and mortality of patients with haemoptysis in a tertiary
care centre.

\section{MATERIALS AND METHODS}

A prospective analysis of patients with haemoptysis in Outpatient and Inpatient wards at Department of Tuberculosis and Respiratory Diseases and Department of Internal Medicine, G.S.V.M. Medical College, Kanpur (India) from January 2015 to June 2016.

\section{RESULTS}

Five hundred and forty six patients with haemoptysis were enrolled during the study period. There were 352 males (64.4\%) and $194(35.6 \%)$ females. Of the patients $79.8 \%(\mathrm{n}=436)$ of patients were nonsmokers, $5.4 \%(\mathrm{n}=30)$ were ex-smokers and $14.6 \%$ $(n=80)$ were current smokers. Majority (71\%) of the patients had Tuberculosis (TB) and $54.2 \%$ of them had active TB. Other major causes were Chronic Bronchitis (8.6\%), Bronchiectasis (5.4\%), Lung cancer (4.5\%), Lung abscess (2.3\%) and idiopathic (2.3\%). Majority $(82.6 \%)$ of the patients had mild haemoptysis and it was severe in $8.7 \%$ patients. There were about $1.25 \%(n=7)$ mortality due to severe haemoptysis. The mean duration of haemoptysis was $3 \pm 0.8,5 \pm 1.2$ and $6 \pm 1.4$ days in mild, moderate and severe haemoptysis cases respectively.

\section{CONCLUSION}

The present study highlighted that pulmonary TB is still the most important cause of haemoptysis in India. Effective case finding and proper treatment could prevent such morbidity and mortality.

\section{KEYWORDS}

Haemoptysis, Tuberculosis, Chronic Bronchitis, Bronchiectasis.

HOW TO CITE THIS ARTICLE: Verma SK, Kumar B, Kumar A, et al. A prospective study to know the aetiology and the final outcome of haemoptysis patients attending a tertiary care centre in North India. J. Evolution Med. Dent. Sci. 2016;5(80):5964-5968, DOI: $10.14260 / \mathrm{Jemds} / 2016 / 1347$

\section{BACKGROUND}

Haemoptysis is the expectoration of blood or blood-tinged sputum from the lungs or tracheobronchial tree and that elicits fear in both the patient and physician. The lung contains two separate vascular systems: the bronchial and the pulmonary vessels. In most cases (90\%), haemoptysis originates from the systemic arterial circulation (bronchial arteries), whereas in five to ten percent cases it originates from the pulmonary arterial circulation. ${ }^{1-2}$ Haemoptysis is a nonspecific symptom and can occur in about more than 100 different clinical conditions. Depending on the underlying

Financial or Other, Competing Interest: None.

Submission 30-08-2016, Peer Review 23-09-2016,

Acceptance 29-09-2016, Published 05-10-2016.

Corresponding Author:

Dr. Sanjay Kumar Verma,

Assistant Professor,

Department of Tuberculosis \& Respiratory Diseases,

Govt. Medical College,

Kannauj-226003, India

E-mail: drskverma78@rediffmail.com

DOI: $10.14260 /$ jemds $/ 2016 / 1347$ disease, haemoptysis may result due to several pathological mechanisms; (A) Infarction of lung tissue (e.g. pulmonary emboli), (B) Vascular engorgement with erosion (e.g. acute infections such as viral or bacterial and chronic infection e.g. bronchiectasis or a toxic exposure such as cigarette smoke, (C) Local hyperaemia (e.g. seen in common bacterial pneumonia and contusion of lung), (D) Vascular engorgement of dilated bronchial vessels along with anastomoses between the pulmonary and bronchial circulations (e.g. occurs in tuberculosis, bronchiectasis, lung abscesses and cystic fibrosis), (E) Necrosis of pulmonary parenchyma (e.g. can be seen in chronic infections such as tuberculosis and in malignant tumours of the lung), (F) Disruption of the pulmonary capillaries can be seen either as a result of increased intravascular pressure (as in mitral stenosis and left ventricular failure) or as a result of disruption of the alveolocapillary basement membrane (e.g. Goodpasture's syndrome), (G) Local friction from the moving fungus ball (e.g. aspergillomas). ${ }^{3}$

The aetiology for haemoptysis varies among different series according to time of publication, the geographic location and the diagnostic tests employed. Most of the data 
from developed countries regarding haemoptysis suggest that bronchiectasis, lung cancer, chronic bronchitis, pneumonia are the leading causes and less commonly by tuberculosis. ${ }^{4-7}$

However, in developing countries, pulmonary tuberculosis still remains to be the major cause of haemoptysis with a high prevalence of the disease.8-10 In India, Pulmonary tuberculosis was the most common cause of haemoptysis in earlier study and other recent study in which tuberculosis was found in $79.2 \%$ of patients. ${ }^{11-12}$ Although tuberculosis is the major cause of haemoptysis, it does not imply that active tuberculosis is present and it may occur even after the disease has been apparently cured.

The purpose of the study was to evaluate the different causes of haemoptysis and to assess the severity of haemoptysis in terms of various diseases.

\section{MATERIAL AND METHODS}

The study was conducted in both the outpatient department and inpatient wards at Department of Tuberculosis and Respiratory Diseases and Department of Internal Medicine, G.S.V.M. Medical College, Kanpur (India) from January 2015 to June 2016. After getting informed consent from the patients, they were included in the study. Patients with bleeding form upper respiratory tract or gastrointestinal tract with bleeding diathesis and on anticoagulant or antiplatelet drugs were excluded from the study. The present study was approved by Institute's Ethics Committee.

After taking a detailed clinical history, patients were subjected to thorough clinical examination and relevant investigations were done.

All patients were instructed to collect the expectorated blood in a glass container and the amount of haemoptysis was recorded by the hospital medical staff and calculated as millilitre equivalent (i.e. one glass container $=100 \mathrm{~mL}$ ). The episodes of haemoptysis were stratified into three groups according to the amount of blood expectorated, i.e. mild: < $100 \mathrm{~mL} /$ day; moderate: $100-400 \mathrm{~mL} /$ day; and massive if > $400 \mathrm{~mL} /$ day or any haemoptysis with signs of asphyxia.

Complete blood count, liver function test, kidney function test, serum electrolyte, fasting and post prandial blood sugar, urinalysis, sputum for AFB, chest X-ray - PA view, bleeding profile. HRCT, ECG, ECHO, Laryngoscopy, Bronchoscopy and other tests were carried out when required. Diagnosis of pulmonary tuberculosis was based on chest radiography and sputum examination for acid fast bacilli as per RNTCP Guidelines. ${ }^{13}$ Patients were classified as old pulmonary TB if following criteria were met: Chest radiograph showed inactive processes such as calcified granuloma/fibrosis, sputum smear negative for AFB, no other symptoms other than haemoptysis. For bronchogenic carcinoma, diagnosis was based on histopathology.

The final diagnosis was made after thorough clinical evaluation and appropriate investigations as mentioned above.

All patients were given appropriate treatment for the control of haemoptysis along with necessary measures for management of the primary disease. Patients with severe haemoptysis were managed with standard critical care protocol with airway protection measures, parenteral fluids/blood transfusion and anti-fibrinolytics.
The duration of haemoptysis was recorded for all enrolled patients irrespective of the severity of haemoptysis.

\section{RESULTS}

Out of 546 patients, 352 were males (64\%) and 194 (36\%) were females with a mean age of 32.78 years and 26.86 years respectively for males and females (Table 1). About $80 \%$ of the patients were nonsmokers and $14.6 \%$ were current smokers and the rest $5.4 \%$ were ex-smokers.

Based on the aetiology, the patients were categorised into different groups [Table 1]. In present study, pulmonary tuberculosis was associated to be the leading cause (71\%) of haemoptysis.

Tuberculosis was associated in $71 \%$ of the patients with $54.1 \%$ of the patients having active pulmonary tuberculosis, while $45.8 \%$ of the patients had old pulmonary tuberculosis. While the other causes of haemoptysis were COPD, Bronchiectasis, Bronchogenic carcinoma, Pneumonia and Lung abscess. The other less common causes of haemoptysis were Allergic Bronchopulmonary Aspergillosis, Solitary Pulmonary Nodule, Tropical Pulmonary Eosinophilia and Chest Trauma (Table 2).

In present study, majority of patients $(82.6 \%)$ had mild haemoptysis, while the moderate and severe forms were observed in $8.6 \%$ and $8.7 \%$, respectively. The severity of haemoptysis among active pulmonary tuberculosis as mild, moderate and severe were $85 \%, 6 \%$ and $7 \%$ respectively. The severity of haemoptysis among old treated pulmonary tuberculosis as mild, moderate and severe were $88 \%, 3 \%$ and $8 \%$ respectively (Table 3 ).

Life-threatening haemoptysis was seen in only $8.7 \%$. All the patients were treated conservatively with bed rest, cough suppressants, sedative and other supportive care. Haemoptysis was stopped between four to seven days in majority of patients (89.7\%).

\begin{tabular}{|c|c|}
\hline $\begin{array}{c}\text { Males }(\mathrm{n}, \%) \\
\text { Females }(\mathrm{n}, \%)\end{array}$ & $\begin{array}{l}352(64 \%) \\
194(36 \%)\end{array}$ \\
\hline Mean Age $( \pm S D)$ years & \\
\hline Males & $32.78( \pm 3.8)$ \\
\hline Females & $26.86( \pm 2.4)$ \\
\hline Smokers & \\
\hline Current (n, \%) & $80(14.7 \%)$ \\
\hline Ex-Smoker (n, \%) & $30(5.5 \%)$ \\
\hline Non-smoker (n, \%) & $436(79.8 \%)$ \\
\hline Severity of haemoptysis & \\
\hline Mild (n, \%) & $451(82.6 \%)$ \\
\hline Moderate $(n, \%)$ & $47(8.6 \%)$ \\
\hline Severe (n, \%) & $48(8.8 \%)$ \\
\hline Mean duration of haemoptysis $( \pm$ SD) days & \\
\hline Mild haemoptysis cases & $3 \pm 0.8$ \\
\hline Moderate haemoptysis cases & $5 \pm 1.2$ \\
\hline Severe haemoptysis cases & $6 \pm 1.4$ \\
\hline Mortality & \\
\hline Mild cases $(n=451)$ & $0(0)$ \\
\hline Moderate cases $(n=47)$ & $1(0.2 \%)$ \\
\hline Severe cases $(n=48)$ & $6(1.25 \%)$ \\
\hline
\end{tabular}




\begin{tabular}{|c|c|c|c|c|}
\hline Sl. No. & Disease Classification & Males & Females & Total \\
\hline 1 & Active Pul TB & $120(34 \%)$ & $90(46.3 \%)$ & $210(38.4 \%)$ \\
\hline 2 & Old Treated Pul TB & $114(32.3 \%)$ & $64(32.9 \%)$ & $178(32.6 \%)$ \\
\hline 3 & Chronic Bronchitis & $39(11 \%)$ & $8(4.1 \%)$ & $47(8.6 \%)$ \\
\hline 4 & Bronchiectasis & $18(5.1 \%)$ & $12(6.1 \%)$ & $30(5.4 \%)$ \\
\hline 5 & Bronchogenic Carcinoma & $20(5.6 \%)$ & $5(2.5 \%)$ & $25(4.5 \%)$ \\
\hline 6 & Pneumonia & $11(3.1 \%)$ & $4(2 \%)$ & $15(2.7 \%)$ \\
\hline 7 & Lung Abscess & $12(3.4 \%)$ & $1(0.5 \%)$ & $13(2.3 \%)$ \\
\hline 8 & Idiopathic & $7(1.9 \%)$ & $6(3 \%)$ & $13(2.3 \%)$ \\
\hline 9 & ABPA & $3(0.8 \%)$ & $2(1 \%)$ & $5(0.9 \%)$ \\
\hline 10 & Solitary Pulmonary Nodule & $2(0.5 \%)$ & - & $4(0.7 \%)$ \\
\hline 11 & Tropical Pul Eosinophilia & $3(0.8 \%)$ & - & $3(0.5 \%)$ \\
\hline 12 & Chest Trauma & $3(0.8 \%)$ & $\mathbf{1 9 4}(\mathbf{3 5 . 3 \% )}$ & $\mathbf{5 4 6}$ \\
\hline Total & \multicolumn{5}{|c|}{ Table 2: Showing Sex-Wise Aetiology of the Study Population (n=546) } \\
\hline
\end{tabular}

\begin{tabular}{|c|c|c|c|c|c|}
\hline Sl. No. & Disease & Mild (N, \%) & Moderate (N, \%) & Severe $(\mathrm{N}, \%)$ & Total \\
\hline 1 & Active Pul TB & $180(39.9 \%)$ & $14(29.7 \%)$ & $16(33.3 \%)$ & 210 \\
\hline 2 & Old Treated TB & $157(34.8 \%)$ & $6(12.7 \%)$ & $15(31.2 \%)$ & 178 \\
\hline 3 & Chronic Bronchitis & $45(9.9 \%)$ & $1(2.1 \%)$ & $1(2 \%)$ & 47 \\
\hline 4 & Bronchiectasis & $11(2.4 \%)$ & $13(27.6 \%)$ & $6(12.5 \%)$ & 30 \\
\hline 5 & Bronchogenic Carcinoma & $18(3.9 \%)$ & $3(6.3 \%)$ & $4(8.3 \%)$ & 25 \\
\hline 6 & Pneumonia & $10(2 \%)$ & $2(4.2 \%)$ & $3(6.2 \%)$ & 15 \\
\hline 7 & Lung Abscess & $10(2 \%)$ & $3(6.3 \%)$ & 0 & 13 \\
\hline 8 & Idiopathic & $10(2 \%)$ & $3(6.3 \%)$ & 0 & 13 \\
\hline 9 & ABPA & $2(0.4 \%)$ & $1(2.1 \%)$ & $2(4.1 \%)$ & 5 \\
\hline 10 & Solitary Pulmonary Nodule & $4(0.8 \%)$ & 0 & 0 & 4 \\
\hline 11 & Tropical Pul Eosinophilia & $1(0.2 \%)$ & $1(2.1 \%)$ & $1(2 \%)$ & 3 \\
\hline 12 & Chest Trauma & $3(0.6 \%)$ & 0 & 0 & 3 \\
\hline Total & & $451(82.6 \%)$ & $47(8.6 \%)$ & $48(8.7 \%)$ & $546(100 \%)$ \\
\hline \multicolumn{6}{|c|}{ Table 3: Severity of Haemoptysis in Study Patients } \\
\hline
\end{tabular}

\begin{tabular}{|c|c|c|c|c|c|c|c|c|c|c|c|}
\hline \multirow[b]{2}{*}{$\begin{array}{l}\text { Sl. } \\
\text { No. }\end{array}$} & \multirow[b]{2}{*}{$\begin{array}{l}\text { Name of } \\
\text { Authors }\end{array}$} & \multirow[b]{2}{*}{$\begin{array}{c}\text { Total } \\
\text { Patients }\end{array}$} & \multicolumn{9}{|c|}{ Causes } \\
\hline & & & 岕 & 胥 & 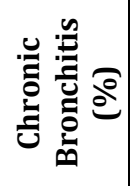 & $\underbrace{a}_{0}$ & 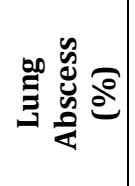 & 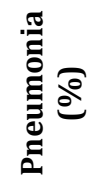 & 䒿 & 预 & 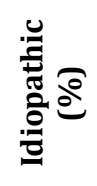 \\
\hline 1 & Jackson CL 14 & 436 & 20 & 32 & 17 & & 12 & 6 & - & - & 8 \\
\hline 2 & Heller R15 & 413 & 2 & 7 & 15 & 39 & 1 & 3 & 1 & 2 & 16 \\
\hline 3 & Abbott $\mathrm{OA}^{5}$ & 497 & 21 & 21 & 2 & 22 & 6 & 2 & 2 & 1 & 4 \\
\hline 4 & Levitt N16 & 717 & 12 & 15 & - & 47 & 5 & 1 & - & 7 & 5 \\
\hline 5 & Moersch HJ6 & 200 & 24 & 27 & 9 & 6 & 5 & 3 & 1 & 1 & 8 \\
\hline 6 & Souders CR7 & 100 & 3 & 37 & 12 & 2 & 2 & - & - & 9 & 18 \\
\hline 7 & Pursel SE17 & 105 & 19 & 23 & 5 & 13 & 3 & 5 & 3 & - & 15 \\
\hline 8 & Lyons HA ${ }^{18}$ & 200 & 12 & 21 & - & 61 & 4 & - & - & - & 2 \\
\hline 9 & Gong H Jr19 & 129 & 24 & 40 & - & 3 & - & 3 & 2 & 4 & 11 \\
\hline 10 & Johnston $\mathrm{H}^{20}$ & 148 & 19 & 1 & 37 & 7 & 2 & 5 & 1 & 1 & 3 \\
\hline 11 & Santiago S21 & 264 & 29 & 0.5 & 23 & 6 & - & 11 & - & - & 22 \\
\hline 12 & Alaoui AY22 & 291 & 34 & 15 & 3.5 & 19 & - & 7 & - & - & 3 \\
\hline 13 & Knott-Craig CJ $^{23}$ & 120 & 5 & 51 & - & 73 & - & 4 & - & - & 8 \\
\hline 14 & McGuinness G24 & 57 & 12 & 25 & 5 & 16 & - & 12 & - & - & 19 \\
\hline 15 & Domoua $\mathrm{K}^{25}$ & 142 & 4.2 & 11.2 & - & 49.3 & - & 13.3 & - & - & - \\
\hline 16 & Hirshberg $\mathrm{B}^{8}$ & 208 & 19 & 20 & 18 & 1 & - & 16 & - & - & 8 \\
\hline 17 & Abal AT10 & 52 & - & 21.2 & 5.8 & 15.4 & - & - & - & - & 25 \\
\hline 18 & Fidan $\mathrm{A}^{26}$ & 108 & 34.3 & 25 & - & 17.6 & - & 10.2 & - & - & - \\
\hline 19 & Unsal E27 & 143 & 18.9 & 22.4 & 5.6 & 11.2 & - & 4.9 & - & - & 13.2 \\
\hline 20 & Rakotoson JL28 & 114 & 1.3 & - & - & 66.6 & - & - & - & - & - \\
\hline 21 & Present Study & 546 & 4.5 & 5.4 & 8.6 & 71 & 2.3 & 2.7 & - & - & 2.3 \\
\hline
\end{tabular}




\begin{tabular}{|c|c|c|c|c|c|}
\hline $\begin{array}{c}\text { Sl. } \\
\text { No. }\end{array}$ & $\begin{array}{c}\text { Name of } \\
\text { Authors }\end{array}$ & $\begin{array}{c}\text { Years of the } \\
\text { Study }\end{array}$ & $\begin{array}{c}\text { Total } \\
\text { Patients }\end{array}$ & $\begin{array}{c}\text { Numbers } \\
\text { Active TB }\end{array}$ & $\begin{array}{c}\text { Numbers } \\
\text { Odd Tuberculosis }\end{array}$ \\
\hline 1 & Prasad R ${ }^{12}$ & 2009 & 476 & $329(69.1 \%)$ & $48(10.08 \%)$ \\
\hline 2 & Pragati R $^{29}$ & 2015 & 140 & $37(26.4 \%)$ & $33(23.5 \%)$ \\
\hline 3 & Patel R $^{30}$ & 2015 & 50 & $19(38 \%)$ & $11(22 \%)$ \\
\hline 4 & Adesh Kumar 31 & 2016 & 462 & $73(15.8 \%)$ & $110(23.8 \%)$ \\
\hline 5 & Nazir Shah & & $45(18.2 \%)$ & $22(8.9 \%)$ \\
\hline 6 & Present Study & 2014 & 246 & $210(38.4 \%)$ & $178(32.6 \%)$ \\
\hline \multicolumn{5}{|r|}{ Table 5: Showing Distribution of Haemoptysis Patients in Active Tuberculosis and Old Treated } \\
Tuberculosis Groups reported by various Indian Studies \\
\hline
\end{tabular}

\section{DISCUSSION}

Review of literatures revealed that aetiological pattern of haemoptysis has changed in the developed countries with pulmonary tuberculosis becoming less important as a common cause. ${ }^{33,15-24}$

Tuberculosis was reported as an important cause of haemoptysis in older articles. In the series of Abbot from Atlanta in the 1940s, the main diagnosis was active tuberculosis in $22 \%$ and bronchiectasis in $21 \%$ of the cases. ${ }^{5}$ While in present study the main aetiology was active pulmonary tuberculosis, old pulmonary tuberculosis in $38.4 \%$ and $32.6 \%$ cases and followed by chronic bronchitis in $8.6 \%$ cases.

Domoua $\mathrm{K}$ et al done a retrospective study in 142 cases to ascertain the main aetiologies of haemoptysis observed in the Pneumophtisiology Unit and they highlighted that the main aetiologies were pulmonary tuberculosis, acute pneumonia, bronchiectasis, pulmonary aspergilloma and bronchogenic cancer in $49.3 \%, 13.3 \%, 11.2 \%, 7.7 \%$ and $4.2 \%$ cases of haemoptysis, respectively. 25 While in present study pulmonary tuberculosis, chronic bronchitis, bronchiectasis and bronchogenic carcinoma were found in 71\%, 8.6\%, 5.4\% and $4.5 \%$ cases respectively. Hirshberg $\mathrm{B}$ et al did a retrospective analysis of 208 patients with haemoptysis and found that Bronchiectasis, Lung Cancer, Bronchitis and Pneumonia in 20\%,19\%,18\% and $16 \%$ cases, respectively. ${ }^{8}$ Another study from Kuwait done to evaluate the aetiology of haemoptysis in 52 patients and they observed haemoptysis in bronchiectasis, old pulmonary tuberculosis, active pulmonary tuberculosis, bronchogenic cancer and chronic bronchitis in $21.2 \%, 17.3 \%, 15.4 \%, 9.6 \%$ and $5.8 \%$ cases, respectively. 10

Fidan $\mathrm{A}$ et al done retrospective analysis of 108 patients admitted to the hospital for haemoptysis and reported that Lung cancer was the leading cause of haemoptysis (34.3\%) followed by bronchiectasis (25.0\%), tuberculosis (17.6\%), pneumonia (10.2\%) and pulmonary embolism (4.6\%). ${ }^{26}$

Unsal E et al did a study among 143 patients with haemoptysis and found that Bronchiectasis was the most common cause of haemoptysis (22.4\%) followed by lung cancer $(18.9 \%)$, active tuberculosis $(11.2 \%)$ and inactive tuberculosis (10.5\%). ${ }^{27}$ Rakotoson JL et al carried out a prospective study in 114 cases of haemoptysis and they found that active pulmonary tuberculosis was the most common aetiology (66.66\%) and less commonly by bronchogenic carcinoma (1.7\%) and aetiology was undetermined in a significant number of cases $(15.78 \%)^{28}$ The details of various other studies are summarised in Table No. 4.

However, in developing countries, pulmonary tuberculosis is still found to be the major cause of haemoptysis.9,11,25 In India, Pulmonary tuberculosis was the most common cause of haemoptysis in various study and it is still the leading cause of haemoptysis as evident from the present study. ${ }^{11}$

Prasad $\mathrm{R}$ et al done a prospective study to evaluate the various aetiologies of haemoptysis and they highlighted that pulmonary tuberculosis was the leading cause of haemoptysis (79.2\%), Bronchogenic carcinoma (5.7\%), chronic bronchitis (4\%), Bronchiectasis (3.8\%) and others $(7.3 \%) .{ }^{12}$

Patel KR et al did a prospective study in 50 cases and reported that tuberculosis was associated in $60 \%$ of the patients with $38 \%$ of the patients having active pulmonary tuberculosis and majority of the patients (60\%) had mild haemoptysis, while moderate haemoptysis was present in $32 \%$ of patients and only four patients (8\%) had severe haemoptysis. ${ }^{30}$ The data in present study found that tuberculosis was associated with $71 \%$ cases and of which active pulmonary tuberculosis and old treated pulmonary tuberculosis were in $38.4 \%$ and $32.6 \%$ cases, respectively. The present study also highlighted that among tuberculosis group, mild form of haemoptysis was encountered in $86 \%$ cases followed by severe form in $7 \%$ cases.

Pragati Rao et al evaluated 140 cases of haemoptysis and they found pulmonary tuberculosis (65\%), bronchogenic carcinoma (10\%), pneumonia (6.4\%), bronchiectasis (4.2\%), lung abscess (2.8\%) and bronchitis (1.4\%). ${ }^{29}$ Kumar A et al did a study in 462 patients of haemoptysis and concluded that sputum AFB-negative post-tubercular sequelae (24\%) was the leading cause. ${ }^{31}$ (The details of various Indian studies are summarised in Table No. 5).12,29-32

All the patients had full investigations to find out the aetiology of haemoptysis, but we could not find the aetiology in $2.5 \%$ of the cases. Saunders and Smith ${ }^{7}$ Santiago et al, ${ }^{21}$ Set et $\mathrm{al}^{34}$ and Miller et $\mathrm{al}^{35}$ also noted the similar findings.

\section{CONCLUSION}

The present study highlighted that pulmonary tuberculosis is still the most important cause of haemoptysis in India, but it can occur in higher frequency in both active pulmonary tuberculosis and old treated pulmonary tuberculosis cases. This study also showed that haemoptysis may occur in various other diseases also apart from tuberculosis. Present study also raises the awareness among general physician about various aetiologies of haemoptysis other than pulmonary tuberculosis.

\section{REFERENCES}

1. Stedman TL. Stedman's medical dictionary. 27th edn. Philidelphia: Lipincott Williams - Wilkins 2000.

2. Lordan JL, Gascoigne A, Corris PA. The pulmonary physician in critical care: Illustrative case 7: assessment and management of massive haemoptysis. Thorac 2003;58(9):814-819. 
3. American thoracic society. The management of hemoptysis. Am Rev Respir Dis 1966;93:471-4.

4. Wolfe JD, Simmons DH. Hemoptysis: diagnosis and management. West J Med 1977;127(5):383-90.

5. Abbott OA. The clinical significance of pulmonary hemorrhage: a study of 1,316 patients with chest disease. Dis Chest 1948;14(6):824-42.

6. Moersch HJ. Clinical significance of hemoptysis. JAMA 1952;148(17):1461-65.

7. Souders CR, Smith AT. The clinical significance of hemoptysis. N Engl J Med 1952;247(21):790-93.

8. Hirshberg B, Biran I, Glazer M, et al. Hemoptysis: etiology, evaluation, and outcome in a tertiary referral hospital. Chest 1997;112(2):440-44.

9. Ashraf 0. Hemoptysis, a developing world perspective. BMC Pulmonary Med 2006;6:1.

10. Abal AT, Nair PC, Cherjan J. Hemoptysis: aetiology, evaluation and outcome. A prospective study in a third world country. Respir Med 2001;95(7):548-52.

11. Rao PU. Hemptysis as a symptom in a chest clinic. Indian J Chest Dis 1960;2:219-22.

12. Prasad R, Garg R, Singhal S, et al. Lessons from patients with haemoptysis attending chest clinic in India. Ann Thorac Med 2009;4(1):10-12.

13. Revised national tuberculosis control programme of India guideline 2016.

14. Jackson CR, Diamond S. Hemorrhage from the trachea, bronchi, and lungs of non-tuberculosis origin. Am Rev Tuberc 1942;46:126-38.

15. Heller R. The significance of haemoptysis. Tubercle 1946;27(5-6):70-74.

16. Levitt N. Clinical significance of hemoptysis. J Mich State Med Soc 1951;50(6):606-10.

17. Pursel SE, Lindskog GE. Hemoptysis: a clinical evaluation of 105 patients examined consecutively on a thoracic surgical service. Am Rev Respir Dis 1961;84(3):329-336.

18. Lyons HA. Differential diagnosis of hemoptysis and its treatment. ATS News 1976;26-30.

19. Gong H, Salvatierra C. Clinical efficacy of early and delayed fiberoptic bronchoscopy in patients with hemoptysis. Am Rev Respir Dis 1981;124(3):221-225.

20. Johnston H, Reisz G. Changing spectrum of hemoptysis: underlying causes in 148 patients undergoing diagnostic flexible fiberoptic bronchoscopy. Arch Intern M 1989; 149(7):1666-8.

21. Santiago S, Tobias J, William AJ. A reappraisal of the causes of hemoptysis. Arch Intern Med 1991;151(12): 2449-51.
22. Alaoui AY, Bartal M, el Boutahiri A, et al. Clinical characteristics and etiology in hemoptysis in a pneumology service: 291 cases. Rev Mal Respir 1992;9 (3):295-300.

23. Knott-Craig CJ, Oostuizen JG, Rossouw G, et al. Management and prognosis of massive hemoptysis. Recent experience with 120 patients. J Thorac Cardiovasc Surg 1993;105(3):394-7.

24. McGuinness G, Beacher JR, Harkin TJ. Hemoptysis: prospective high-resolution CT/bronchoscopic correlation. Chest 1994;105(4):1155-62.

25. Domoua K, N'Dhatz M, Coulibaly G, et al. Hemoptysis: main etiologies observed in a pneumology department in Africa. Rev Pneumol Clin 1994;50(2):59-62.

26. Fidan A, Ozdogan S, Oruc 0, et al. Hemoptysis: a retrospective analysis 108 cases. Respir Med 2002; 96(9):677-80.

27. Unsal E, Koksal D, Cimen F, et al. Analysis of patients with hemoptysis in a reference hospital for chest diseases Tuberkulozve Toraks Dergisi 2006;54(1):34-42.

28. Rakotoson JL, Rakotondravelo SJ, Rakotomizao JR. Haemoptysis in madagascar: etiologies of 114 cases. Med Trop (Mars) 2010;70(1):101-104.

29. Rao PD, Reddy CRN, Padmaja A. Aetiology of haemoptysis -study in a medical college. International Journal of Current Medical and Applied sciences 2015;8(1):24-6.

30. Patel KR, Patel AK, Godhania N. Evaluation of patients with haemoptysis attending the chest clinic of tertiary referral hospital. Int J Res Med 2015;4(2):91-3.

31. Kumar A, Gupta AK, Gautam AK, et al. Not all hemoptysis is tuberculosis-think of other etiologies. A lesson from a chest clinic in a rural tertiary care center in central India. Int J Med Sci Public Health 2016;5(8):1662-1664.

32. Shah NN, Wani MA, Khursheed SQ, et al. Etiology of hemoptysis in India revisited. Int J Med Health Sci 2016;5(1):9-13.

33. Bidwell JL, Pachner RW. Hemoptysis: diagnosis and management. Am Fam Physician 2005;72(7):1253-60.

34. Set PA, Flower CD, Smith IE, et al. Haemoptysis: comparative study of the role of CT and fibreoptic bronchoscopy. Radiology 1993;189(3):677-80.

35. Miller AB, Boothroyd AE, Edwards D, et al. The role of computed tomography (CT) in the investigation of unexplained haemoptysis. Respir Med 1992;86(1):39-44. 